\title{
ARTIFICIAL NEURAL NETWORK BASED MPPT ALGORITHM FOR MODERN HOUSEHOLD WITH ELECTRIC VEHICLE
}

\author{
Ján Morgoš*, Peter Klčo, Karol Hrudkay \\ University Scientific Park, University of Zilina, Zilina, Slovakia \\ *E-mail of corresponding author: jan.morgos@uniza.sk
}

\section{Resume}

This paper deals with implementation of artificial neural network in the maximum power point tracking (MPPT) controller algorithm for modern household where electric vehicle (EV) was purchased. The proposed MPPT algorithm was designed to achieve the best possible efficiency of the MPP (maximum power point) tracking and the best possible energy harvesting to charge the EV's battery. The artificial neural networks have strong advantage in fast input to output response of signals and the finding of MPP is faster than in commonly used algorithms. In this article, the optimised simulation model based on artificial neural network will be introduced. The proposed artificial neural network algorithm was designed for non-shielded photovoltaic panels.

\section{Article info}

Received 24 May 2021

Accepted 23 August 2021

Online 24 November 2021

\section{Keywords:}

artificial neural network, MPPT algorithm,

electric vehicle,

battery,

photovoltaic,

(photo-voltaic) PV panel,

high efficiency

\section{Introduction}

In recent years there has been growing interest in producing electricity from solar energy and other renewable energy sources (RES). Since it is truly renewable energy source, it is a valuable non-polluting alternative to fossil fuel energy sources in industrial, household or transport applications. Main disadvantages of the solar energy are relatively high costs, lower efficiency of photovoltaic (PV) systems (37 - 40\%) and dependence on weather conditions, as well as difficulties of storing this kind of energy [1]. In addition, the maintenance and cleaning of solar panels is not easy in some cases, i.e. on high-rise buildings. With assistance of the PV panels, or other renewable energy sources, the electric grid energy consumption and electricity bills can be easily reduced. The whole PV panel industry has been growing market creating new job opportunities and new opportunities for research. The effort of many research teams is aimed at efficiency maximization of the solar energy conversion. In addition, the smart control methods can increase the efficiency significantly. New materials with higher efficiency are researched and new algorithms for the PV systems power control, as well [1-4].

\section{Theoretical background}

The electrical power of the PV cells can vary significantly during the day, therefore maximum power point tracking method is strongly required to maximize generated power. The PV panel used is modelled as a single-diode circuit with current source and serial and parallel resistances [4]. Principal schematic of one PV cell is illustrated in Figure 1. The mathematic relation between the PV cell's output current and output voltage can be described as:

$$
I_{C E L L}=I_{P V}-I_{S}\left[\exp \left(\frac{V+I R_{S}}{V_{T}}\right)-1\right]-\frac{V+I R_{S}}{R_{p}},
$$

where:

$I_{C E L L}$ output current of PV module,

$V_{P V}$ output voltage,

$I_{P V}$ photocurrent,

$I_{s}$ diode saturation current,

$V_{T} \quad$ the thermal voltage,

$R_{p} \quad$ equivalent serial resistance,

$R_{s}^{p}$ equivalent serial resistance.

The thermal voltage is expressed as:

$V_{T}=\frac{n * k * T * N_{s}}{q}$,

where:

$n$ ideality factor,

$k \quad$ Boltzmann constant [1.381 x 10-23 J/K],

$T$ temperature of the cell,

$N_{s} \quad$ number of solar cells in the PV module connected in series,

$q \quad$ elementary electron charge [4-6]. 


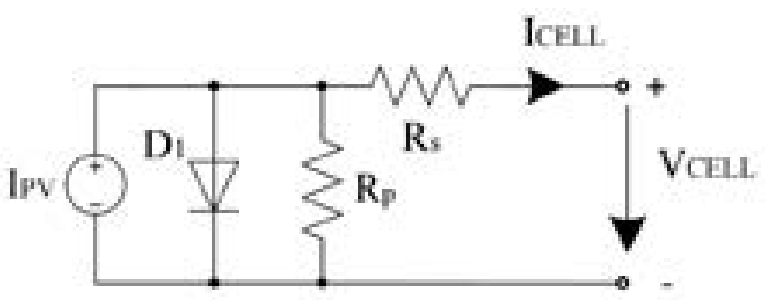

Figure 1 Principal schematic of diode model of PV panel

Artificial neural networks (ANN) are considered as mathematical-computational models inspired by biological neural networks. Neural networks were used in various areas, like robotics, function approximation, regression analysis, time series prediction, classification, modelling or data processing [7]. The ANN have become a standard tool in computer science for the function approximation of various digital patterns and data inputs. and are also considered to be one of the most successful computer classification models.

According to the universal approximation theorem, the ANN with just 1 hidden layer can approximate any continuous function. ANNs can be therefore considered as efficient function approximators. These statements deal predominately with existence of solution in the form of unique weight coefficients, they do not say anything about exact method how to find the most optimal parameters of a neural network. It is not always easy to find solution that represents global minimum of the cost function instead of localy minimum [8]. Figure 2 shows principal diagram of the feed-forward neural network.

\section{MPPT controller based on ANN}

System consists of PV panels, isolated switching converter, household battery and the EV's battery. In this system, only the unidirectional energy flow is realized from the PV panel to the electric vehicle battery back. Due to cloud shielding, the solar energy flow is not continuous; it is necessary for the system to use the household battery to supply energy during disturbances caused by the clouding of the PV panels.

The trained ANN implemented to the control system (microcontroller) controls the switching converter with the requested current $I^{*}$ to create the optimal load for the PV panels to achieve maximum charging performance. Reference current signal is internally converted into the pulse width modulation (PWM) signals used to switching MOSFET transistors in switching converter [9-10]. The ANN controls the converter with using of PV panel voltage, PV panel current and PV panel temperature signals. For the safety reasons, the battery voltage and current are connected to control block and the system is switched off if any error occurs. Big advantage of this setup with household battery is supplying the EV charger without interruptions and energy flow fluctuations during the clouding. Principal block diagram of used model is shown in Figure 3.

The solar irradiance and the PV panel temperature are usually chosen as input data for neural network in MPPT control. The advantage is possibility to simulate photovoltaic panel in simulation software MATLAB. However, the sensors for measurement of solar irradiance are much more expensive and the whole solution is therefore less cost-effective. Random electrical current, voltage of $\mathrm{PV}$ panels and real temperature of photovoltaic panels are also used as input data (input neurons) for the trained neural network [10-15].

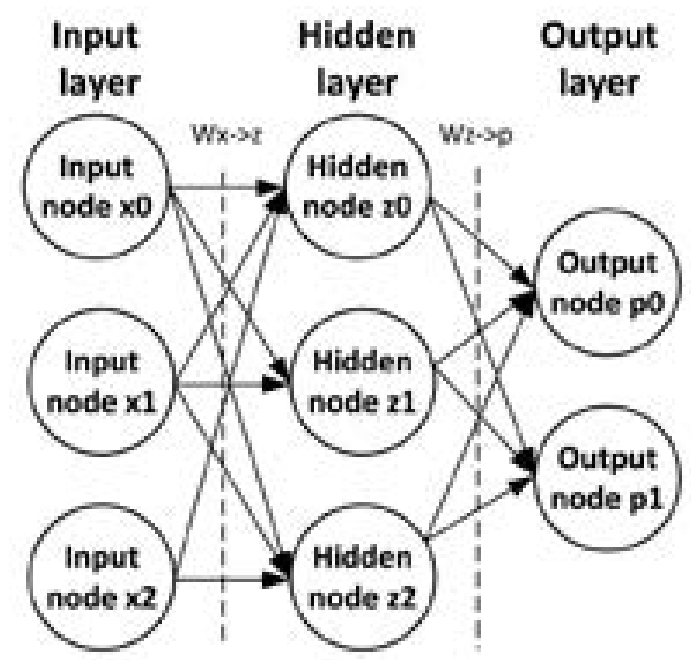

Figure 2 Principal diagram of neural network 


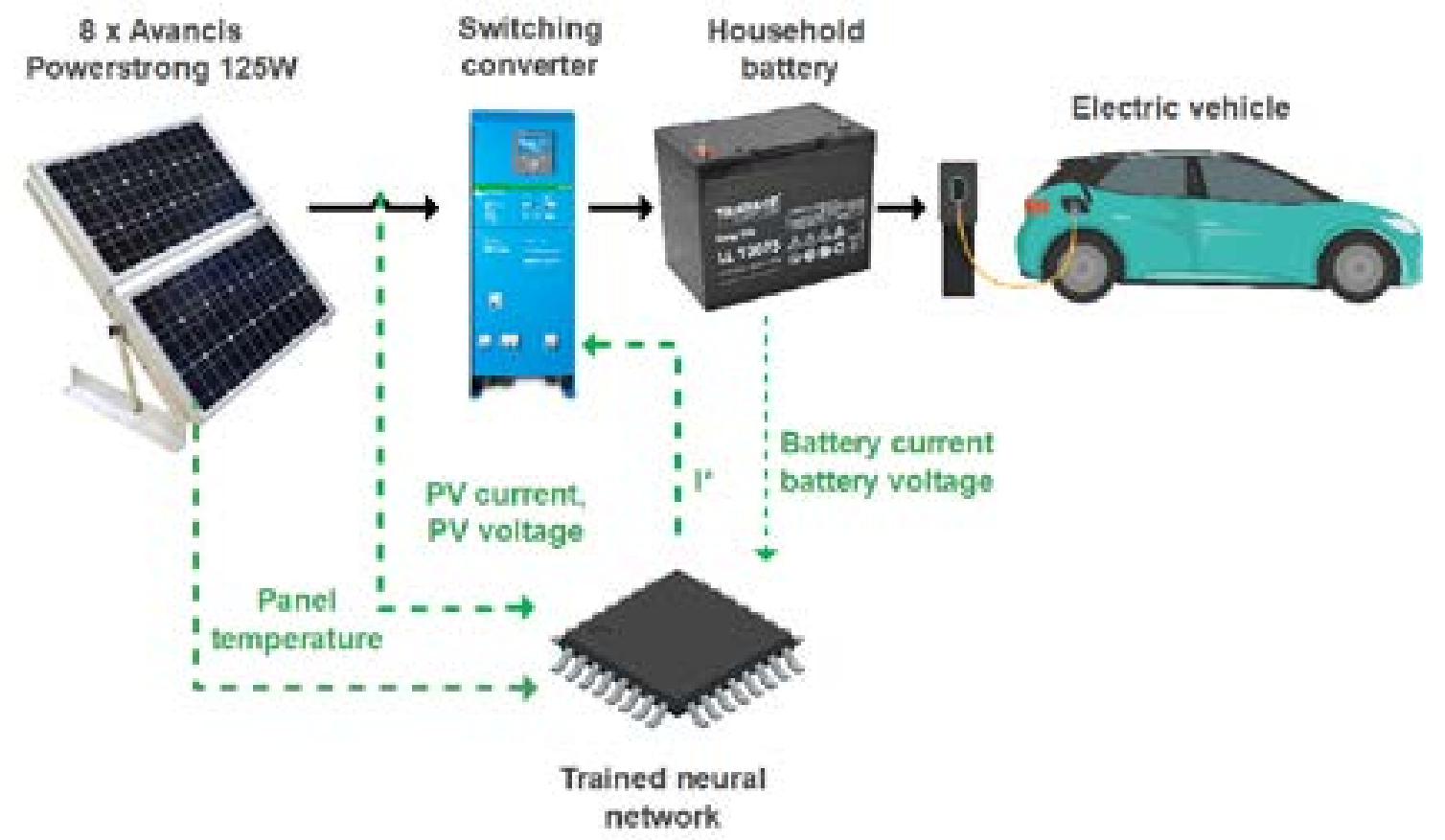

Figure 3 Principal schematics of the MPPT system based on ANN

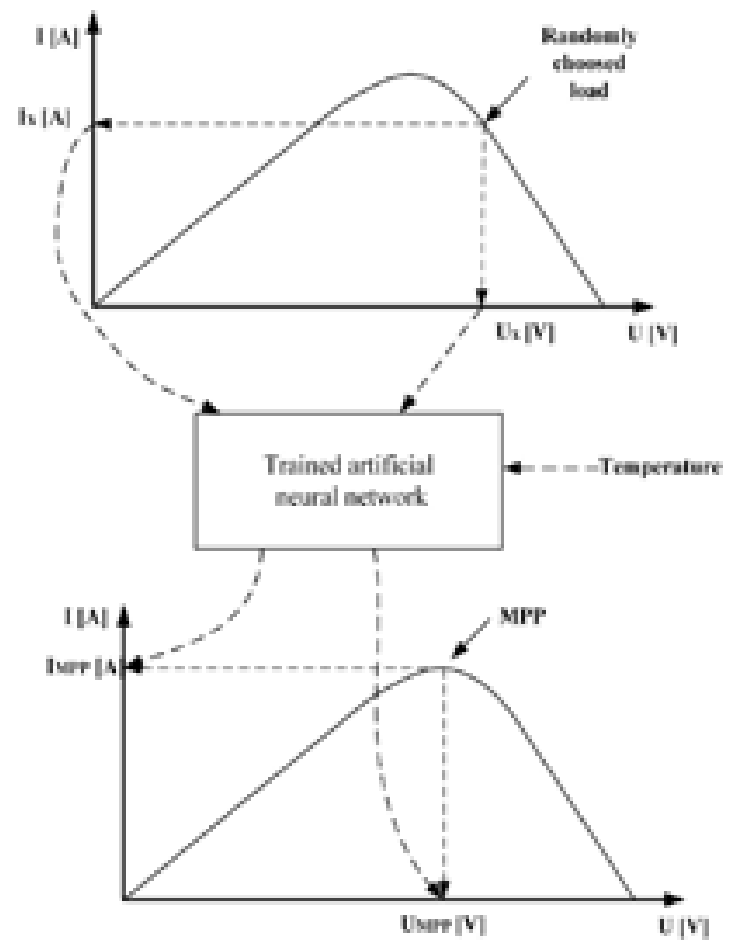

Figure 4 Principal working diagram of proposed MPPT algorithm based on ANN

The MPP searching algorithm, due to trained values, estimates the PV current, PV voltage and the PV power at the maximal power point (3 output neurons). Than in the MPPT algorithm the estimated MPP current by the ANN is requested by the switching converter interpreted by the change of duty of the PWM signal. This cycle periodically in the infinite loop. The graphical interpretation of the proposed MPPT algorithm is shown in Figure 4 [16].

\section{Methods}

The real PV installation contained $8 \times$ ( 2 in series, 4 in parallel) amorphous CSI (copper-selenium-indium) Avancis Powermax 125W panels. The installation of PV panels is shown in Figure 5. Electrical parameters of the PV panel are described in Table 1.

The neural network's input data were obtained from the simulation of $\mathrm{P}-\mathrm{V}$ and I-V characteristics of the PV 


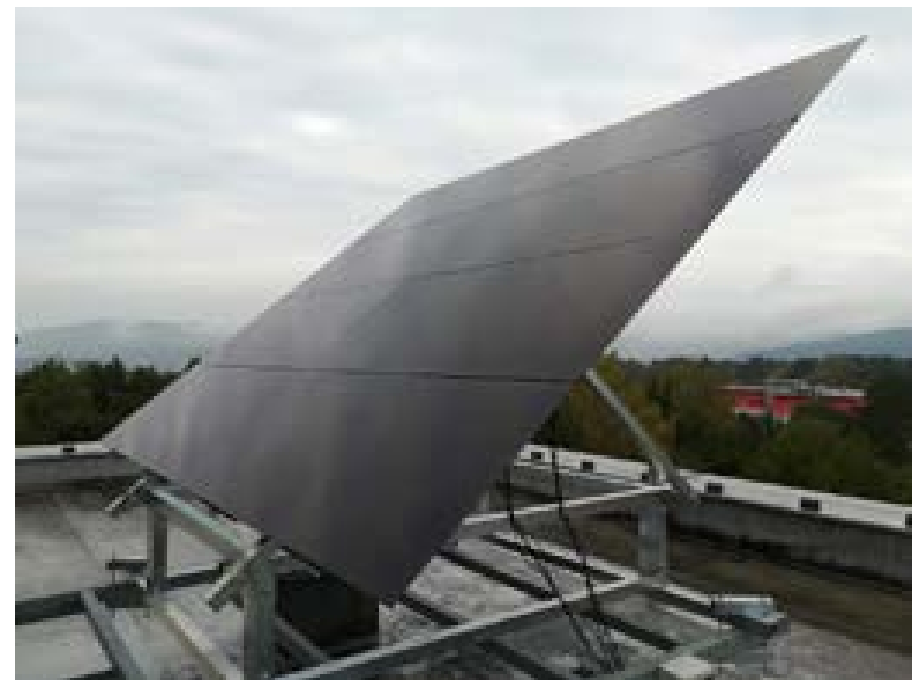

Figure 5 The PV string installation on the University Science Park's roof in Zilina, Slovakia

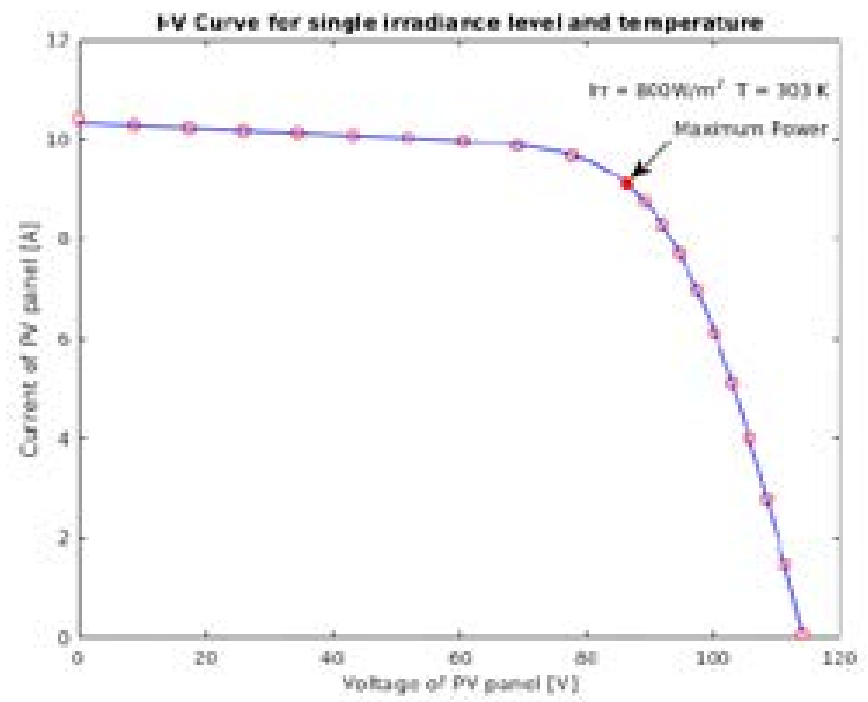

Figure $6 I-V$ curve of the PV panel

Table 1 The specification of single Avancis PowerMax 125 PV

\begin{tabular}{lc}
\hline Maximum power & $125 \mathrm{~W}$ \\
\hline Voltage at maximum power & $44 \mathrm{~V}$ \\
Current at maximum power & $2.84 \mathrm{~A}$ \\
Open circuit voltage & $59.3 \mathrm{~V}$ \\
Short circuit voltage & $3.22 \mathrm{~A}$ \\
Nominal operating voltage & $52.6 \mathrm{~V}$ \\
\hline
\end{tabular}

panels in MATLAB Simulink There were 96 different temperature levels $\left(\min -20{ }^{\circ} \mathrm{C}\right.$; max $75{ }^{\circ} \mathrm{C}$; step $1{ }^{\circ} \mathrm{C}$ ) and 100 irradiance levels $\left(\min 10 \mathrm{~W} / \mathrm{m}^{2} ; \max 1000 \mathrm{~W} /\right.$ $\mathrm{m}^{2}$; step $10 \mathrm{~W} / \mathrm{m}^{2}$ ). During the PV panels simulation more than 200000 unique combinations of mentioned parameters were created. The temperature, electrical current and voltage of the PV panel were chosen as input data of the neural network for MPPT control. Since MATLAB Simulink model of PV panel uses temperature and solar irradiance as input data, the reference values of electrical voltage and current of PV panels had to be obtained for the neural network training. These electrical parameters were depended on temperature and solar irradiance level and were obtained in simulation. Figure 6 describes the process of gathering electrical parameters from I-V characteristics of the PV panels. The 10 points were chosen from point of maximum power (red circle) towards the zero current and 10 points towards the maximum current of photovoltaic panel characteristics. The intervals were linearly spaced along the $\mathrm{x}$ axis; therefore, one solar irradiance value corresponded to 21 current and voltage values. 


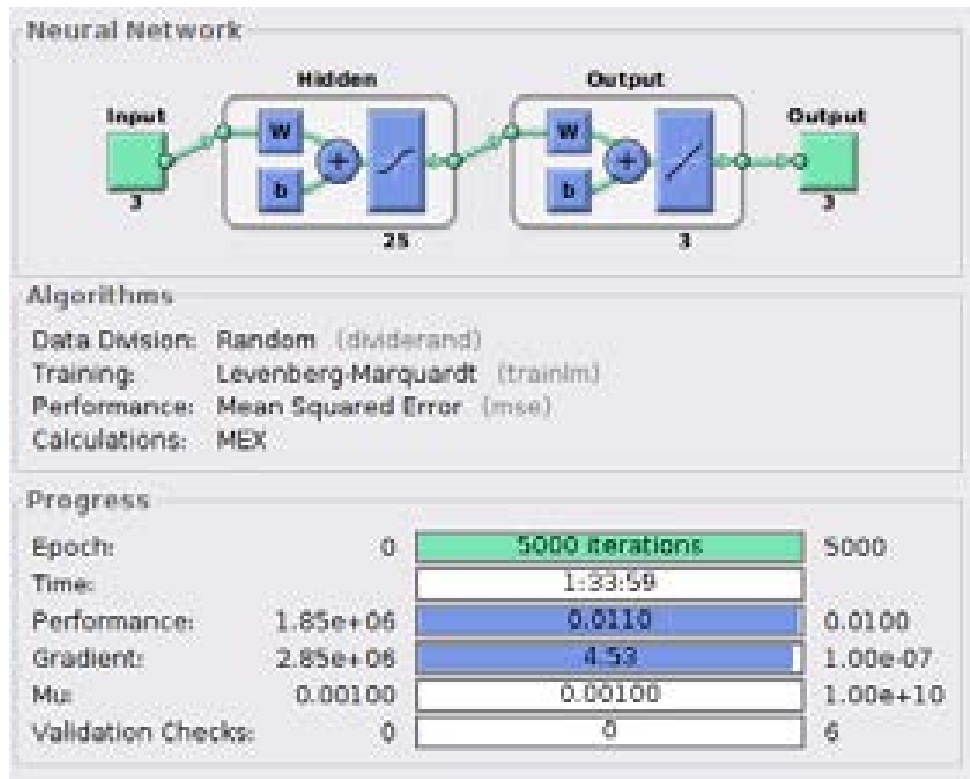

Figure 7 The proposed architecture of the ANN for MPPT controller

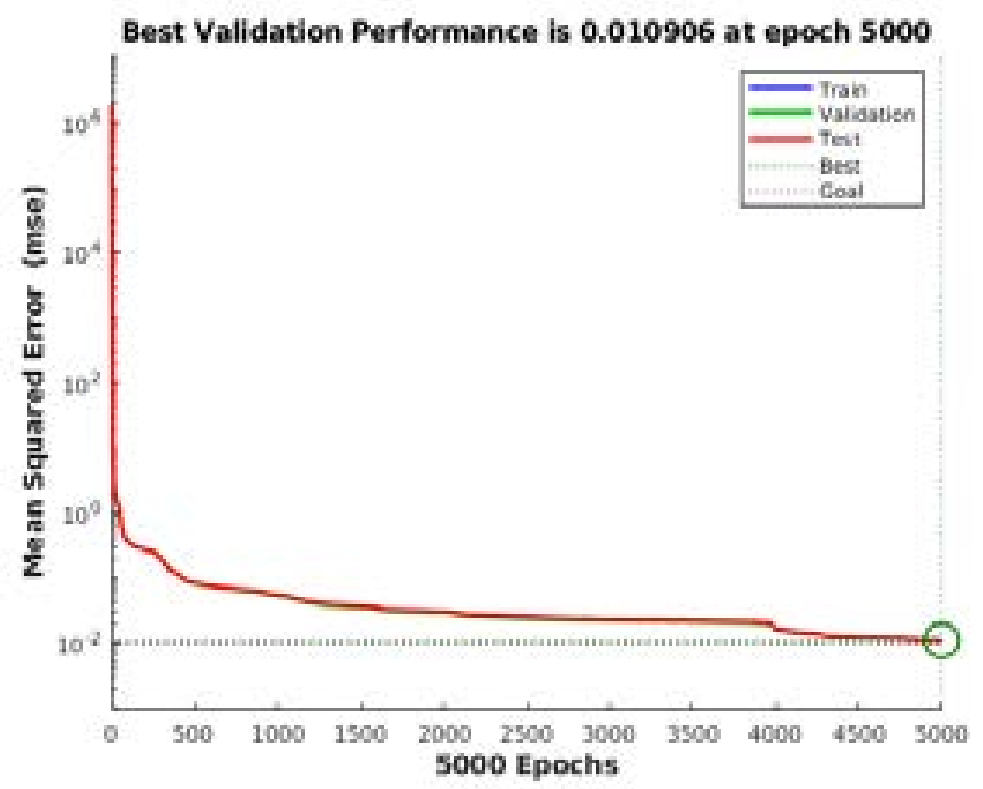

Figure 8 The ANN's training performance vs. epochs

The neural network contains 3 input neurons - input current, input voltage and input temperature. Hidden layer contains 25 neurons and output layer contains 3 neurons. These 3 neurons (outputs) interpret the PV current ( $1^{\text {st }}$ neuron $), P V$ voltage $\left(2^{\text {nd }}\right.$ neuron) that occurs at the maximum output power ( $3^{\text {rd }}$ neuron) for specified input temperature of PV panels. The sigmoidal activation function was used in the hidden layer and the linear activation function in the output layer. The network was trained with Levenberg-Marquardt optimization algorithm [7]. Number of neurons in the hidden layer was obtained experimentally as a number with the best network's MSE (mean squared error) in an interval $(5 ; 50)$. Due to improving the training time, the conjugate gradient optimization method was chosen and every ANN architecture was trained 10 times by resetting state of random number generator at each trial. In order to potentially implement the neural network in a microcontroller, the basic type of the feedforward 2-layer neural network (FFNN) was chosen. The ANN was implemented with MATLAB and its architecture is shown in Figure 7.

\section{Simulation results}

The dataset was divided to training (70 \%), validation $(15 \%)$ and testing $(15 \%)$ set. The effort to prevent the ANN from overfitting was important, therefore the division of data to individual sets was random and training was stopped after increasing of network's error in validation set. Several optimization 
Table 2 The ANN performance in individual cases ( $R^{*}$ is rounded to 7 decimal places)

\begin{tabular}{ccc}
\hline Case & MSE & Corr. coef. $\mathbf{R}^{*}$ \\
\hline 1 & 0.0251 & 1.0 \\
2 & 0.0524 & 1.0 \\
3 & 0.1011 & 1.0 \\
4 & 0.0249 & 1.0 \\
5 & 0.0536 & 1.0 \\
6 & 0.0801 & 1.0 \\
7 & 0.0251 & 1.0 \\
8 & 0.0524 & 1.0 \\
9 & 0.0199 & 1.0 \\
10 & 0.0149 & 1.0 \\
\hline
\end{tabular}
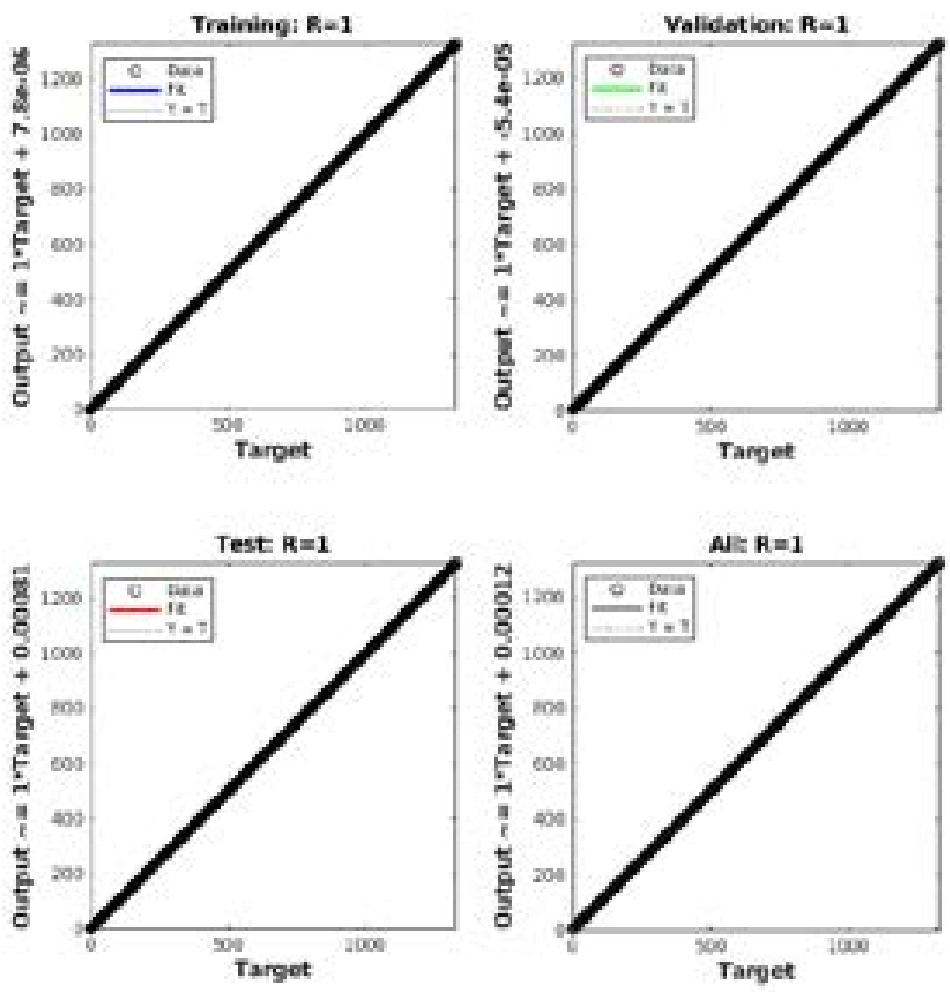

Figure 9 Regression plots across training, validation and test set

methods for the neural network training have been compared. Finally, the Levenberg-Marquardt algorithm was chosen, since the best network's performance and speed of convergence were achieved. The training's stop criterium was met at finishing 5000 iteration cycles or MSE (mean-square error) lower than 0.0001. Figure 8 shows the dependence of the neural network MSE on iteration cycles. The convergence speed is very high and MSE decreased more than 1000 times during the initial iterations. This result is consistent over validation and testing set, as well as in the whole spectrum of tested values.

Table 2 shows neural network's mean square error after 1000 training iteration cycles and regression coefficients in 10 random training cases. No significant increasing of MSE parameter in validation set was observed. The correlation coefficient $R$ is related to linear correlation between target and predicted values of neural network model. $\mathrm{R}$ is considered as indicator of goodness of neural network's fit for the observation data and is expressed as:

$$
R=\frac{\sum_{i=1}^{n}\left(x_{i}-\bar{x}\right)\left(y_{i}-\bar{y}\right)}{\sqrt{\sum_{i=1}^{n}\left(x_{i}-\bar{x}\right)^{2}} \sqrt{\sum_{i=1}^{n}\left(y_{i}-\bar{y}\right)^{2}}}
$$

where:

$x_{i} \quad$ predicted value of sample $i$

$\bar{x}$ mean of predicted values

$y_{i} \quad$ target value of sample $i$

$\bar{y}$ mean of target values

$n$ sample size (number of patterns) 


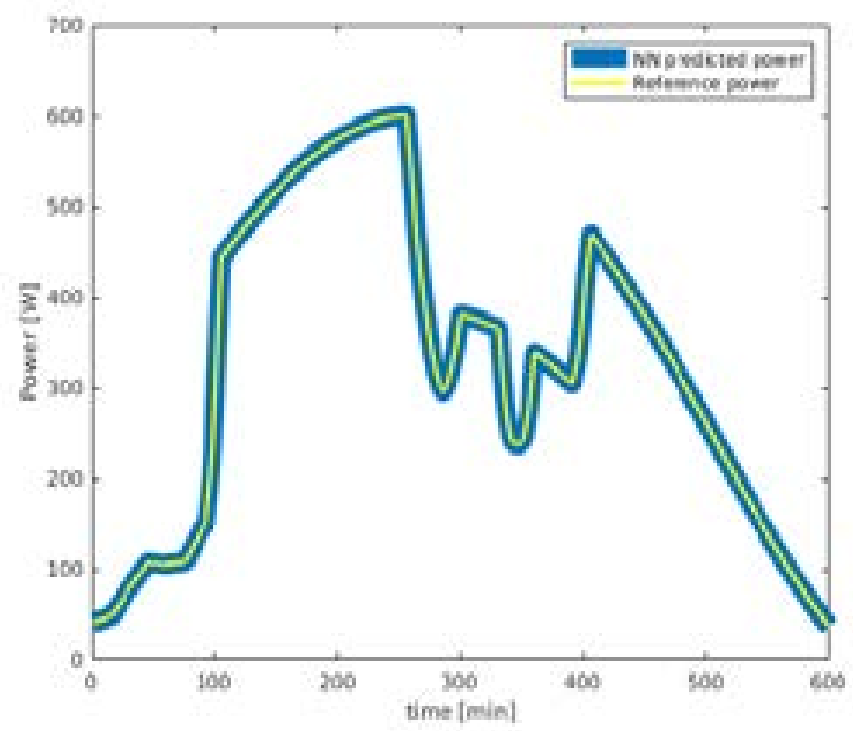

Figure 10 The comparison of ANN's predicted power versus the reference power

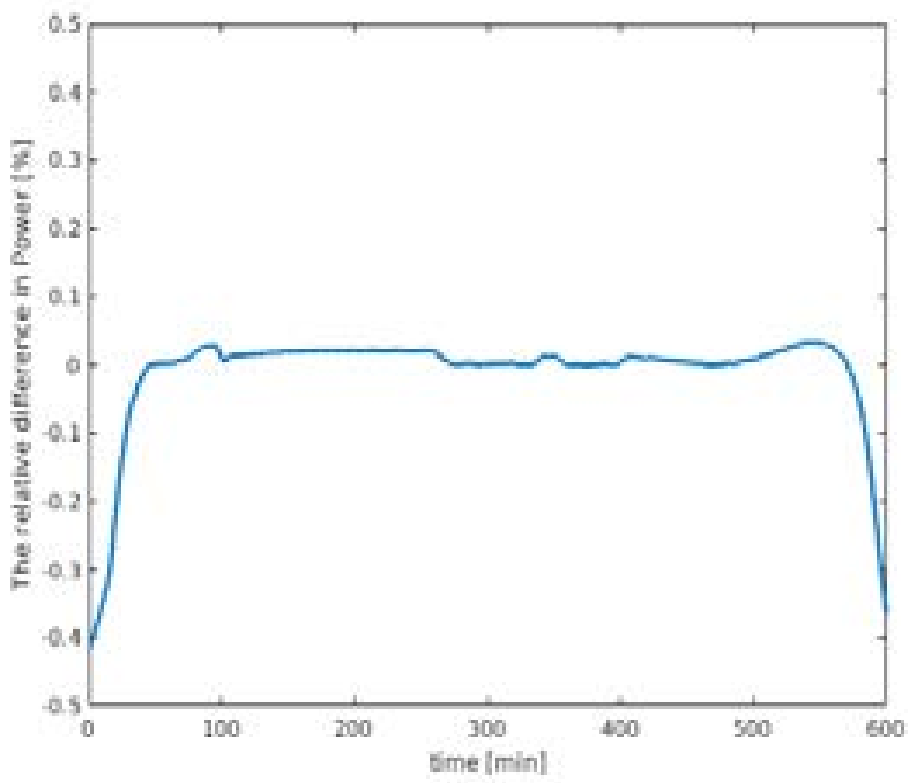

Figure 11 The relative difference in ANN predicted power versus the reference power

Figure 9 shows regression plots of training, validation and test sets. The regression coefficient in all sets is close to 1 . These results successfully confirmed the ANN ability to track maximum power with high accuracy.

In order to verify capability of the trained neural network to track the maximum power of the PV panel, the numerical simulation was performed. The simulation input data were collected from Copernicus Atmosphere Monitoring Service (CAMS) after registration on the SoDa web service [17]. The time series of temperature and beam irradiation for the actual geographical location and weather condition were obtained for year 2020 . These data were analysed with respect to cumulative absolute difference in solar irradiance during the day.
The September 12, 2020 was chosen as an example for graphic presentation of $\mathrm{NN}$ performance since the solar irradiance was changing significantly during the day. The irradiance and temperature were used for computing the reference values of maximum power (blue curve in Figure 10) of the PV panels simulated in MATLAB Simulink. The ANN simulated maximum power corresponds to yellow curve. Since the curves were completely overlapped, different widths of lines were chosen. These results confirmed neural network's potential to quickly respond to sudden changes of solar irradiance, since the network error did not increase in predicted maximum power.

Figure 10 shows the relative difference in predicted power of used neural network model versus the reference 
power obtained from the atmospheric data. The same irradiance and temperature obtained from online CAMS service on September 12, 2020 were used for computation of power reference values [18]. The relative difference in predicted and real power, as shown in Figure 11, was obtained below $0.1 \%$ during the most of the day and did not exceed $0.5 \%$ at sunrise and sunset periods.

\section{Conclusions}

In this article, the MPPT algorithm, based on artificial neural network, for modern household with an electric vehicle, was presented. All the parameters of the PV system and MPPT controller were designed to achieve the best maximum power point tracking efficiency and maximum charging performance of the EV's battery. The final architecture of neural network, layers and activation functions were described. The main advantage of the proposed model is simplicity of obtaining the neural network input data such as voltage, current or temperature. The solar irradiance sensors are not needed. The electrical current, voltage and temperature of PV panels are easily measurable variables with affordable sensors. The neural network model's input data were obtained from computer simulations of the PV panels at wide range of solar irradiance and temperature values. The exact method of generating electrical current and voltage values for neural network input was introduced. This method requires I-V curves of a particular PV panel under various solar irradiance values. The needed I-V curves of that PV panel can be generated in MATLAB Simulink, the solar irradiance and temperature are only required parameters. The neural network's performance was tested in computer simulation based on satellitederived solar irradiance data. The presented neural network MPPT model can quickly respond to sudden changing of solar irradiance values. The response time depends mainly on speed of input data acquisition since the neural network model contains only 150 weight connections. Partial shading conditions of the PV systems were not the object of this research. Additional sensors, measuring the shielded area of a PV system, could provide important information for neural network in order to deal with partial PV panels shading conditions. These conditions will be a part of the authors' future research.

\section{Acknowledgement}

This publication was realized with support of Operational Program Integrated Infrastructure 2014 2020 of the project: Innovative Solutions for Propulsion, Power and Safety Components of Transport Vehicles, code ITMS 313011V334, co-financed by the European Regional Development Fund.

\section{References}

[1] CAMERON, L., VAN DER ZWAAN, B. Employment factors for wind and solar energy technologies: a literature review. Renewable and Sustainable Energy Reviews [online]. 2015, 45, p. 160-172. ISSN 1364-0321. Available from: https://doi.org/10.1016/j.rser.2015.01.001

[2] LEWIS, N. S. Toward cost - effective solar energy use. Science [online]. 2007, 315(5813), p. $798-801$. ISSN 1095-9203. Available from: https://doi.org/10.1126/science.1137014

[3] POLMAN, A., KNIGHT, M., GARNETT, E. C., EHRLER, B., SINKE, W. C. Photovoltaic materials: present efficiencies and future challenges. Science [online]. 2016, 352(6283), aad4424. ISSN 1095-9203. Available from: https://doi.org/10.1126/science.aad4424

[4] RASHID, M. H. Power electronics handbook [online]. 4.ed. Oxford: Butterworth-Heinemann, 2018. ISBN 9780128114070, eISBN 9780128114087. Available from: https://doi.org/10.1016/C2016-0-00847-1

[5] LAUDANI, A., MANCILLA-DAVID F., RIGANTI-FULGINEI F., SALVINI A., Reduced-form of the photovoltaic five-parameter model for efficient computation of parameters. Solar Energy [online]. 2013, 97, p. 122-127. ISSN 0038-092X. Available from: https://doi.org/10.1016/j.solener.2013.07.031

[6] MANCILLA-DAVID F., RIGANTI-FULGINEI F., LAUDANI A., SALVINI A., A neural network-based lowcost solar irradiance sensor. IEEE Transactions on Instrumentation and Measurement [online]. 2014, 63(3), p. 583-591. ISSN 0018-9456, eISSN 1557-9662. Available from: https://doi.org/10.1109/TIM.2013.2282005

[7] SIRAT, J. A., NADAL, J. P. Neural trees: a new tool for classification. Network: Computation in Neural Systems [online]. 1990, 1(4), p. 423-438. ISSN 0954-898X, eISSN 1361-6536. Available from: https://doi.org/10.1088/0954898X_1_4_003

[8] HAYKIN, S. Neural networks: a comprehensive foundation. Vol. 2. Hoboken, New Jersey, USA: Prentice Hall, 1998. ISBN 0-13-273350-1.

[9] KELLNER, J.; PRAZENICA, M. Design of charging system with the elimination of electric arc during switching off. In: 13th International Conference ELEKTRO 2020: proceedings. 2020. CFP2048S-USB. ISBN 978-1-7281-7541-6. 
[10] KELLNER, J., PRAZENICA, M. Example of inrush current elimination after connection of high input DC voltage. Przeglad Elektrotechniczny [online]. 2020, 96(8), p. 102-105. ISSN 0033-2098. Available from: https://doi.org/10.15199/48.2020.08.20

[11] SHERIFF, I. M., SESHDARI, S. Artificial neural network based MPPT of solar photovoltaic cells. International Journal of Innovative Research in Science, Engineering and Technology [online]. 2018, 7(5), p. 5972-5982. ISSN 2347-6710, eISSN 2319-8753. Available from: https://doi.org/10.15680/IJIRSET.2018.0705175

[12] LAUDANI, A., FULGINEI, F. R., SALVINI, A., LOZITO, G. M., MANCILLA-DAVID, F. Implementation of a neural MPPT algorithm on a low-cost 8-bit microcontroller. In: 2014 International Symposium on Power Electronics, Electrical Drives, Automation and Motion: proceedings [online]. IEEE. 2014. eISBN 978-1-4799-4749-2, p. 977-981. Available from: https://doi.org/10.1109/SPEEDAM.2014.6872101

[13] CHORFI, J., ZAZI, M., MANSORI, M. A new intelligent MPPT based on ANN algorithm for photovoltaic system. In: 2018 6th International Renewable and Sustainable Energy Conference IRSEC 2018: proceedings [online]. IEEE. 2018. p. 1-6. Available from: https://doi.org/10.1109/IRSEC.2018.8702858

[14] DI VINCENZO, M. E.; INFIELD, D. Artificial neural network for real time modelling of photovoltaic system under partial shading. In: International Conference on Sustainable Energy Technologies ICSET: proceedings [online]. IEEE. 2010. ISBN 9781424471928, p. I-5. Available from: https://doi.org/10.1109/ICSET.2010.5684464

[15] YILMAZ, U., TURKSOY, O., IBRIKICI, T., TEKE, A. Estimation of electrical characteristics and maximum power point of photovoltaic panel. Journal of Electrical Systems [online]. 2017, 13(2), p. 255-265. ISSN 1112-5209. Available from: https://journal.esrgroups.org/jes/papers/13_2_4.pdf

[16] LOUKIL, J., DERBEL, N. Control strategy for a photovoltaic/lead-acid batteries energy production system. Journal of Electrical Systems [online]. 2019, 15(3), p. 459-479. ISSN 1112-5209. Available from: https://journal. esrgroups.org/jes/papers/15_3_9.pdf

[17] FARANDA, R., LEVA, S., MAUGERI, V. MPPT techniques for PV systems: energetic and cost comparison. In: IEEE Power and Energy Society General Meeting: proceedings [online]. IEEE. 2008. ISSN 1932-5517. Available from: https://doi.org/10.1109/PES.2008.4596156

[18] CAMS Radiation Service - Atmosphere Monitoring Service [online] [accessed 2021-02-03]. Available from: http://www.soda-pro.com/web-services/radiation/cams-radiation-service 